\title{
Characterization and Calibration Test 1709 Pressure Sensor For Air Compressor Pressure Control
}

\author{
Noor Yulita Dwi Setyaningsih ${ }^{1}$, Friska Christiantoro ${ }^{2}$, Mohammad Iqbal $^{3}$ \\ \{Noor.yulita@umk.ac.id ${ }^{1}$, friskachris007@gmail.com² ${ }^{2}$ mohammad.iqbal@umk.ac.id ${ }^{3}$ \} \\ Electrical Engineering University of Muria Kudus, Gondangmanis, Bae - Kudus ${ }^{123}$
}

\begin{abstract}
Sensors are used to change the system of manual control to automatic. This research is about controlling the air pressure of a compressor automatically utilize pressure sensors 1709 . The sensors used in the form analog sensors, so that the necessary process of characterization and calibration. This is important to know the relationship between the sensor used with a standard measuring tool and find out the errors provide information about air pressure is detected. From research conducted in 1709 to characterize the pressure sensor $\mathrm{Y}=0.2088 \mathrm{X}-19686$. Where $\mathrm{X}$ is the value of analog sensors, $\mathrm{Y}$ is the value of the measured air pressure from the tool ukut digital manometer. With the regression value of 0999 , these data imply that there is a very strong linear correlation. With a percent error rate, the air pressure data reading is $0.01 \%$ and the 1709 pressure sensor accuracy level is $99.3 \%$.
\end{abstract}

Keywords: characterization, calibration, sensor 1709 percent error, correlation, accuracy.

\section{Introduction}

Many jobs in the current era have taken advantage of technological developments to be able to assist and facilitate the performance of humans. The application of existing technology development at this time can improve efficiency in terms of time, effort and the results of such work. Many cottage industries opened bike shop, where the business is to provide solutions to problems faced by humans, namely when filling vehicle tires. In the process of filling tires of vehicles still use manual, in which the tire is filled with air using a compressor without knowing how the wind pressure, only with estimates. Even to the wind pressure according to need.

With the use of air pressure varies according to need. because it is to facilitate the adjustment of air pressure according to the needs, it requires an air pressure control system. The presence of an air pressure control system, this affected the long tool life time and to maintain safety. At the existing controls at the moment still using manual methods, which utilize springs to control the air pressure, and use the spring as a limit air pressure. It is still difficult for users, because users are not free to determine the desired air pressure limit.

With the existence of these problems, so we need a system of automatic control of air pressure. To replace the manual system to an automated control system, we need a tool to replace the human role in controlling. Where the tool in this research is the sensor. Sensors play a role here to replace human work in controlling the air pressure according to the needs. In this study, the sensor is a pressure sensor used in 1709, this sensor can be used to read the

ICCSET 2018, October 25-26, Kudus, Indonesia

Copyright (C) 2018 EAI

DOI 10.4108/eai.24-10-2018.2280518 
pressure of the water, air, oil. The sensor output is analog, wherein the data released is in the form of analog data is not digital data.

Where it can be seen that each value derived from a quantitative measurement is only an estimate of the value of the properties measured. So with such a condition that requires a quality indicator that can be applied consistently, can be measured and has meaning [1]. These conditions need to be considered because the sensor used is an analog sensor output from the sensor is still in the form of analog data or voltages, so it takes a comparative parameters to be fixed indicator in determining the results according to the standard. And the condition of the sensor in this study are still using analog sensors, so it takes a sensor characterization process to determine the equation of the performance of the sensor is then carried out to compare the sensor calibration standard measurement tool to measure in order to obtain information about how far the measuring instrument to the standard deviation of the value used. A measuring instrument can be said to be in good condition and fit for use if such devices can provide realtime information [2][3].

Associated with calibration, the industrial world is increasingly aware of the importance of performing the calibration of production equipment, it is linked with the level of product produced. Testing the quality of a product can be done by testing the material before it is used, where by comparing the results of the measuring instrument. With the calibration can also be known error or deviation from the material being tested.

Because of the importance of process characterization and calibration of pressure sensors in 1709 , then in this study to characterize the process and sensor calibration. Characterization process performed to determine the employment equation, measuring range, the specifications of this instrument and the calibration process to determine the condition of the sensor used.

\section{Method}

The method used in this study utilizes a simple regression analysis method. Simple regression analysis is used to process data obtained analog sensor to determine the relationship between analog data with the data measuring instrument in the form of equations. From equation obtained will be used to serve as the race in the process of calibrating the pressure sensor 1709. The analytical methods used in this study one of them is a correlation. Where the correlation is used to determine the relationship between the sensor used with a standard measuring tool in the market. For the correlation equation used is shown in equation 1.

$$
r=\frac{n\left(\sum x y\right)-\left(\sum x\right)\left(\sum y\right)}{\sqrt{n\left(\sum x^{2}\right)-\left(\sum x\right)^{2}} \sqrt{n\left(\sum y^{2}\right)-\left(\sum y\right)^{2}}}[4]
$$

With the value of the regression equation criteria are as follows:
a) 0.00 to 0.199
: Correlation Very Weak.
b) 0.20 to 0.399
: Correlation Weak.
c) 0.40 to 0.599
: Correlation Enough.
d) 0.60 to 0.799
: Strong correlations.
e) 0.80 to 1.000
: Correlation Very Strong 
The process in this study can be seen in Figure 1.

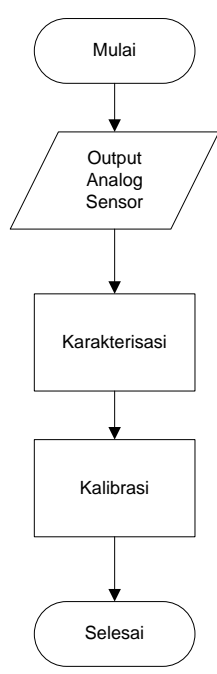

Fig. 1. Flow Research.

From the initial process image data acquisition analog sensor is paired with a pressure value that is read by a digital manometer measuring instrument. Data retrieval is done twice analog sensors with pressure levels of 20-100psi. Once the sensor analog data and pressure readings measuring instrument digital manometer is obtained, the next step is to characterize the sensor with a simple regression method. Simple regression method is used to determine the relationship between the value of analog sensors with pressure readings using digital manometer measuring devices, while the data sought is the value of regression and equations. For regression equation used in this study, can be seen in Equation 2.

Simple regression equation $\mathrm{Y}=\mathrm{A}+\mathrm{BX}[4]$ Where :

$\mathrm{Y}=$ Variable result (Dependent).

$\mathrm{A}=$ Constant.

$\mathrm{B}=$ regression coefficient (slope).

$\mathrm{X}=$ variable factor (Independent)

With value calculation formula $\mathrm{A}$ and $\mathrm{B}$ as follows:

$$
\begin{gathered}
a=\frac{\left(\sum y\right)\left(\sum x^{2}\right)-\left(\sum x\right)\left(\sum x y\right)}{n\left(\sum x^{2}\right)-\left(\sum x\right)^{2}}[4] \\
b=\frac{n\left(\sum x y\right)-\left(\sum x\right)\left(\sum y\right)}{n\left(\sum x^{2}\right)-\left(\sum x\right)^{2}}[4]
\end{gathered}
$$

After the characterization equation is obtained, where the value of $\mathrm{X}$ is an analog sensor data value and the $\mathrm{Y}$ value is the value of pressure measuring devices digital manometer. The 
next step for this research is the process of calibrating the sensor. The calibration process is used to determine the specifications of the pressure sensor 1709. In addition, it can be seen the performance of the sensors used in 1709 , and from this calibration process can be used to prove whether the sensor 1709 can provide information, in this case is the value of a valid air pressure. And can determine the level of accuracy and the average error of the sensor 1709. As can be seen in the accuracy equation 5 and the equation to determine the average value of the sensor reading errors can use the equation 6.

$$
\begin{gathered}
\text { Akurasi }=100 \%-\text { Rata }- \text { rata Error } \%[5] \\
\text { Error rata }- \text { rata } \%=\frac{y-x}{y} x 100 \%[5]
\end{gathered}
$$

The process of reading the data for the characterization of the sensors 1709 can be seen in Figure 2.

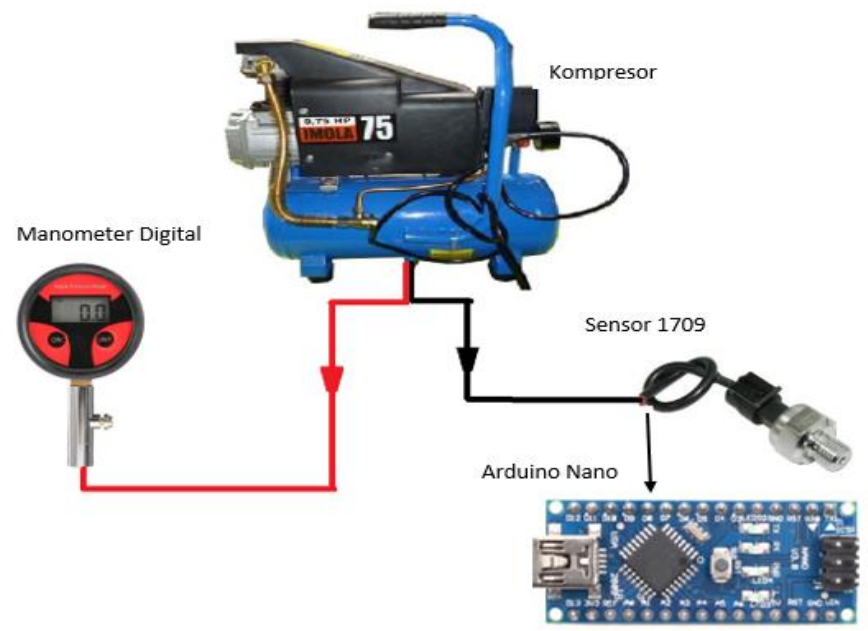

Fig. 2. Characterization Process Sensor Data 1709.

From Figure 2 components required for the characterization of the process in 1709 is the compressor pressure sensor, the sensor 1709, manometer and arduino nano. Compressors are used to provide air pressure which then manometer digital detects the amount of air pressure out on the compressor, under the same conditions of pressure sensors 1709 also reads the air pressure coming out of the compressor, but the sensor output in 1709 is still an analog data not as a measuring tool manometer which is already digital output. Due to the condition of the pressure sensors in 1709 which is still analog so it takes a signal conditioning in the form of ADC (Analog Digital Converter). This signal conditioning is used to convert the sensor analog data into digital data, this study utilizes nano arduino to read analog data 1709 pressure sensor. 


\section{Results and Discussion}

Characterization of pressure sensors in 1709 , done by reading the value of analog sensors and pressure values using a measuring instrument digital manometer. Characterization of sensors are used to determine the value (psi) of air pressure. Because analog sensors utilized in the study, which is still a voltage output. In fact, for the next research data required is the air pressure (psi), so the process of characterization is very important. In previous research, no one has done the characterization of the sensors in 1709 , so this study has the objective to determine the response rate and the error of the readings of air pressure (psi) from the sensor 1709.

Pressure sensor characterization testing is done in 2 times the test to determine the level of accuracy and precision of the sensor readings in the same measurement conditions, while the test results can be seen in Table 1 .

Table 1. The test result data reading analog sensors with measuring devices.

\begin{tabular}{ccccccc}
\hline & \multicolumn{2}{c}{ testing I } & \multicolumn{2}{c}{ testing II } & \multicolumn{2}{c}{ Average } \\
\cline { 2 - 6 } No. & $\begin{array}{c}\text { Analog } \\
\text { Sensor } \\
\text { Data }\end{array}$ & $\begin{array}{c}\text { Measurement } \\
\text { Data (psi) }\end{array}$ & $\begin{array}{c}\text { Analog } \\
\text { Sensor } \\
\text { Data }\end{array}$ & $\begin{array}{c}\text { Measurement } \\
\text { Data (psi) }\end{array}$ & $\begin{array}{c}\text { Analog } \\
\text { Sensor } \\
\text { Data }\end{array}$ & $\begin{array}{c}\text { Measurement } \\
\text { Data (psi) }\end{array}$ \\
\hline 1 & 565 & 98 & 556 & 98 & 560.5 & 98 \\
2 & 526 & 90 & 528 & 90 & 527 & 90 \\
3 & 477 & 80 & 479 & 80 & 478 & 80 \\
4 & 430 & 70 & 431 & 70 & 430.5 & 70 \\
5 & 381 & 60 & 384 & 60 & 382.5 & 60 \\
6 & 334 & 50 & 335 & 50 & 334.5 & 50 \\
7 & 286 & 40 & 287 & 40 & 286.5 & 40 \\
8 & 236 & 30 & 237 & 30 & 236.5 & 30 \\
9 & 189 & 20 & 190 & 20 & 189.5 & 20 \\
\hline
\end{tabular}

From Table 1 we can see the results of testing the readability value of analog sensors with the conditions of air pressure of 20psi until 100psi. Measurement sensor output is data output ADC is conducted under the same air pressure. This is done to determine the level of accuracy and precision of the sensor 1709 . From the data it can be seen that the relationship between the analog value and the pressure value is directly proportional, where the greater value detected pressure measuring instrument digital manometer the analog value greater pressure sensor 1709 also. Tests carried out twice to determine the stability of the sensor analog data output 1709. From the data in Table 1, can be displayed in a graph is presented in Figure 3: 


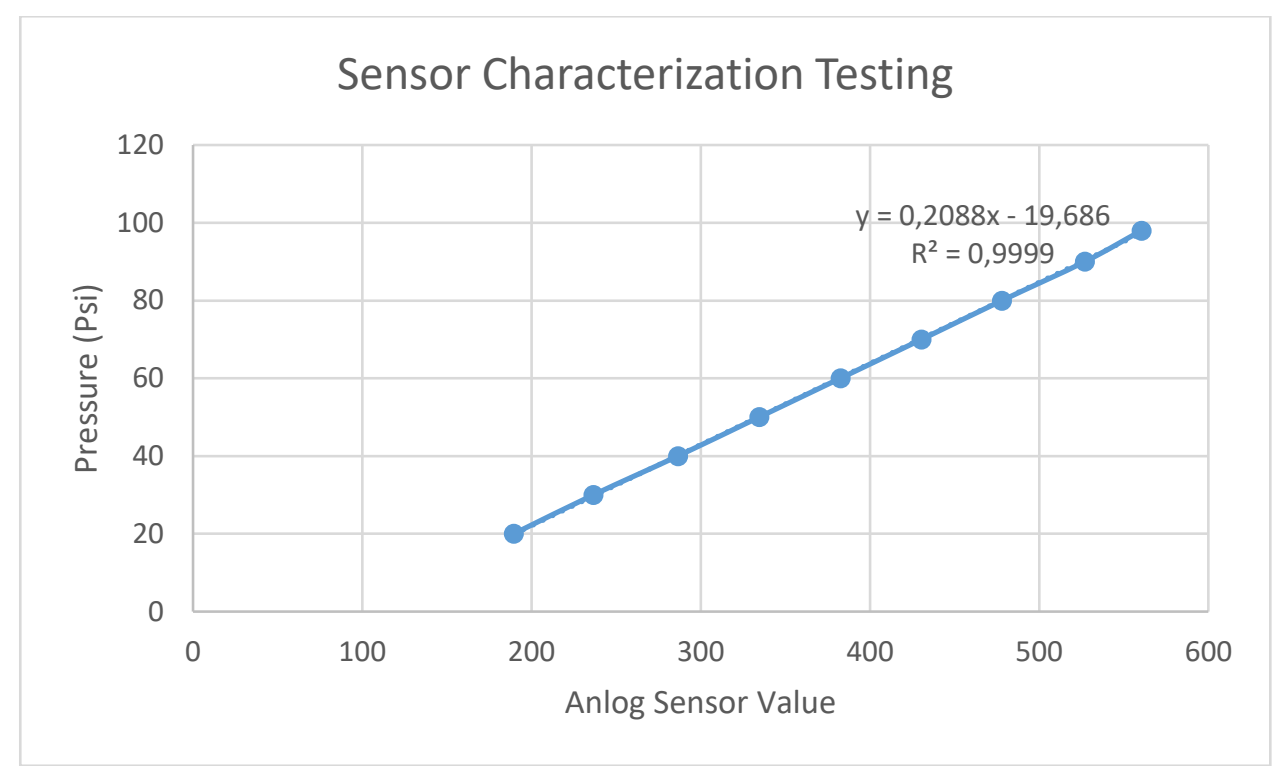

Fig. 3. Sensor Characterization 1709.

Obtained from the equation: $\mathrm{Y}=0.2088 \mathrm{X}-19686$, and $\mathrm{Y}$ is the value of air pressure that is sought and $X$ is an analog value of pressure sensor 1709. With a value of 0.9999 regression, regression value of this means that there is a very strong linear correlation between the value of analog sensors with value digital manometer measuring instrument. Tests 1 and 2 testing, do the subsequent data processing is the process of calibrating the sensor. Sensor calibration data can be seen in Table 2 .

Table 2. Pressure sensor calibration test data in 1709 .

\begin{tabular}{cccccccc}
\hline \multicolumn{3}{c}{ testing I } & \multicolumn{5}{c}{ testing II } \\
\hline $\begin{array}{c}\text { Sensor } \\
\text { Data }\end{array}$ & $\begin{array}{c}\text { Data } \\
\text { Measurement }\end{array}$ & $\begin{array}{c}\text { Error } \\
(\%)\end{array}$ & accuracy & $\begin{array}{c}\text { Sensor } \\
\text { Data }\end{array}$ & $\begin{array}{c}\text { Data } \\
\text { Measurement }\end{array}$ & $\begin{array}{c}\text { Error } \\
(\%)\end{array}$ & accuracy \\
\hline 98.5 & 98 & 0.01 & $99.49 \%$ & 98.87 & 98 & 0.01 & $99.11 \%$ \\
90.41 & 90 & 0.005 & $99.54 \%$ & 90.89 & 90 & 0.01 & $99.01 \%$ \\
80.24 & 80 & 0.003 & $99.70 \%$ & 80.715 & 80 & 0.009 & $99.11 \%$ \\
70.27 & 70 & 0.004 & $99.61 \%$ & 70.53 & 70 & 0.008 & $99.24 \%$ \\
60.205 & 60 & 0.003 & $99.66 \%$ & 60.45 & 60 & 0.008 & $99.25 \%$ \\
50.24 & 50 & 0.005 & $99.52 \%$ & 50.275 & 50 & 0.006 & $99.45 \%$ \\
40.275 & 40 & 0.007 & $99.31 \%$ & 40.3 & 40 & 0.007 & $99.25 \%$ \\
30.21 & 30 & 0.007 & $99.30 \%$ & 30.115 & 30 & 0.004 & $99.62 \%$ \\
20.35 & 20 & 0.02 & $98.25 \%$ & 20.22 & 20 & 0.011 & $98.90 \%$ \\
\hline
\end{tabular}


Calibration is a process to determine the condition of the sensor is still linear or nonlinear, it is still fit for use or need replacement. Maximum tolerance limits of the use of a sensor error is $\pm 5 \%$. From the results obtained in 1709 sensor calibration, the accuracy of the pressure sensor in 1709 amounted to $99.3 \%$ and the average value of a reading error by the air pressure sensor value of $0.01 \%$. Value errors of calibration results that are less than 5\%, it is stated that the condition sensor decent and good in 1709 for use in subsequent studies related to detecting air pressure in the compressor automatically.

\section{Conclusion}

From research characterization and calibration of pressure sensor 1709 to control the air pressure compressor, it can be concluded that:

1) 1709 pressure sensor is used as a tool worthy substitute manual control to automatic control of air pressure in the compressor detection because the sensor reading error rate of $0.01 \%$.

2) 1709 sensor characterization equation is $\mathrm{Y}=0.2088 \mathrm{X}-19686$ with a value of $\mathrm{R}=$ 0.999 .

3) The accuracy of the sensors in 1709 amounted to $99.3 \%$.

\section{References}

[1] S. E. Nuraini, T. Sussana, "Ketidakpastian Pengukuran Pada Metode AANC untuk Analisis Cuplikan Sedimen," Pros. PPI-PDIPTN, pp. 256-262, 2007.

[2] P. Y. Isnaini, "Penentuan Ketidakpastian Kalibrasi Besar," Din. Kerajinan dan Batik, vol. 27, pp. $37-42,2010$.

[3] S. G. S. Hariyadi, F. Hidayanti, "Rancang Bangun Sistem Kalibrasi Alat Ukur Tekanan Rendah," J. Ilm. GIGA, vol. 18, pp. 22-28, 2015.

[4] S. S. F. Nicola, M. Mintadi, "Hubungan Antara Konduktivitas, TDS ( Total Dissolved Solid ) dan TSS ( Total Suspended Solid ) dengan Kadar Fe2+ dan Fe Total pada Air Sumur Gali di Daerah Sumbersari, Puger dan Kencong Kabupaten Jember," Pros. Semin. Nas. Kim. 2015, pp. 159-164, 2015.

[5] A. F. C. L. D. Jones, "Electronic_Instruments_and_Measurements," Electron. Instruments Meas. Second Ed., pp. 1-174, 1991. 